\title{
An undergraduate curriculum to study health risk factors of college students in Guam: The Pacific Islands Cohort of College Students (PICCS)
}

\author{
Yvette Paulino ( $\nabla$ paulinoy@triton.uog.edu ) \\ University of Guam \\ Anthony Ada \\ University of Guam \\ John Dizon \\ University of Guam \\ Elisha-Rose J. Benavente \\ University of Guam \\ Katherine Mary De Luna Campbell \\ University of Guam \\ Breinard Cristobal \\ University of Guam \\ Alexandria Daughtry \\ University of Guam \\ Lorenz Michael O. Estabillo \\ University of Guam \\ Victoria Diana Cruz Flisco \\ University of Guam \\ Grazyna Badowski \\ University of Guam \\ Margaret Hattori-Uchima \\ University of Guam
}

\section{Research Article}

Keywords: Curriculum Development, Epidemiology, Health Disparities, Minority Health, Native Hawaiian or Other Pacific Islander, Non-Communicable Diseases, Obesity, Public Health, Social Determinants of Health

Posted Date: February 18th, 2021

DOI: https://doi.org/10.21203/rs.3.rs-199645/v1

License: (c) (1) This work is licensed under a Creative Commons Attribution 4.0 International License. Read Full License 


\begin{abstract}
Background: The non-communicable disease epidemic among Pacific Islanders prompted the Pacific Island Health Officers Association to declare a health emergency throughout the United States-Affiliated Pacific Islands (Resolution \#48-01). Subsequently, the University of Guam Health Science Program initiated the Pacific Islands Cohort of College Students (PICCS). The purpose here is to (1) describe the PICCS development and (2) estimate 2016 baseline health indicators of participants enrolled in PICCS.
\end{abstract}

Methods: Research theory and application were incorporated in undergraduate core courses. Student researchers led data collection, analysis, and dissemination of a cross-sectional study of 417 college students conducted September-December 2016. Self-reported information on demographics, health risk behaviors, and awareness were ascertained. Height and weight were measured to estimate weight status. Mean (standard deviation) for ratio variables and frequency (percentages) for categorical variables were calculated.

Results: The PICCS curriculum resulted in multiple successes: 22 abstracts, one manuscript, five acceptances to health leadership programs, four travel awards, and one federal grant. Mean age of the 2016 PICCS research participants was 22.5 (3.6) years. Majority was female (55\%). The predominant race/ethnic groups were single-race Asians (49\%) and Pacific Islanders (31\%) followed by Other/Mixed Ethnicity (20\%). Majority reported health risk behaviors: inadequate sleep (63\%), high stress (66\%), frequent fast-food consumption (63\%), infrequent fruit/vegetable intake (81\%), and sedentary lifestyle (64\%). Overweight and obesity (49\%) were also a concern.

Conclusion: The PICCS curriculum produced multiple research successes. Integration in an undergraduate program will sustain the monitoring of college student health risk behaviors and informing of targeted intervention strategies.

\title{
Background
}

Noncommunicable diseases (NCDs), including cardiovascular diseases, cancer, respiratory diseases, and diabetes, remain among the leading causes of death globally. Combined NCDs account for $71 \%$ (41 of 57 million) of all deaths, ${ }^{1}$ with a projected increase to 52 million by 2030 . In the Pacific region, $40 \%$ of the 9.7 million residents endure NCDs while $75 \%$ of deaths are NCD-related. ${ }^{2}$ To mitigate NCDs in the Pacific, stakeholders developed and circulated the NCD Roadmap suggesting a multisectoral approach to implement four key strategies: control tobacco use through increased taxes, reduce consumption of foods and drinks linked to NCDs through policies, improve efficiency and impact, and improve evidence base for decision making. ${ }^{3}$ Monitoring and surveillance of NCD-related health indicators have been prioritized in many islands, including those affiliated with the United States (US).

\section{Response to NCDs in the US Affiliated Pacific Islands}

The US-Affiliated Pacific Islands (USAPIs) are home to over half-million people spread across Oceania including the islands of American Samoa, Guam, Commonwealth of Northern Marianas, Republic of the Marshalls, Republic of Palau, and the Federated States of Micronesia (Pohnpei, Chuuk, Kosrae and Yap). Representatives from the USAPIs form the Pacific Islands Health Officers' Association (PIHOA). In 2010, PIHOA declared a Regional State of Health Emergency due to the NCD epidemic in the USAPI through Board Resolution \#48-01. ${ }^{4}$ Prior to the resolution, the Pacific Chronic Disease Council (PCDC) developed a Pacific NCD Collaborative Initiative assessing the USAPIs' NCD-related services and expanding the population outreach. ${ }^{5}$ Subsequently, Board Resolution \#48- 01 reinforced the development of an NCD strategic plan among the USAPIs. PIHOA guided the islands on development and implementation of their strategic plan through participation in an epidemiology training program for Pacific health workforce ${ }^{6}$ adopted from the Pacific Data for Decision Making (DDM) Program. ${ }^{7}$

\section{Involving undergraduate students in training, research, and service to address NCDs}

Pacific DDM concepts were adopted by the University of Guam Health Science Program. During 2013 and 2014, the program piloted a health survey among students attending the university. The survey evolved into a student-centered project later named the Pacific Islands Cohort of College Students (PICCS). The Pacific DDM concepts and the PICCS activities were phased into selected Health Science Program core courses described in Table 1. Throughout the program, students were introduced to anthropometry (HS200); NCD risk factor assessment (HS216); study design and survey development (HS405); PICCS data collection (HS416), analysis (MA387), dissemination (HS451); and translation (HS491) and application (HS498) of curricular concepts.

PICCS is an annual cross-sectional study that will progress to an epidemiologic cohort. This paper describes the development of the PICCS curriculum, and the health indicators of participants enrolled when the curriculum was formalized in 2016.

Table 1. Selected core courses supporting the Pacific Islands Cohort of College

Students (PICCS) curriculum of the B.S. Health Sciences Program, University of Guam 


\begin{tabular}{|ll|}
\hline Course & Content \\
\hline HS200 Health and Wellness & Exposure to PICCS anthropometry \\
\hline HS216 Introduction to Public Health & Exposure to PICCS assessment of NCD risk factors \\
\hline HS405 Epidemiology & Exposure to PICCS study design and methodology \\
\hline HS416 Research in Health Sciences & Collection of PICCS data \\
\hline MA387 Statistics for Sciences & Analysis of PICCS data \\
\hline HS451 Research and Report Writing & Dissemination of PICCS findings \\
\hline HS491 Current Topics in Health Sciences & Translation of PICCS and other health topics \\
\hline HS498 Internship in Health Sciences & Application of PICCS and other program knowledge and skills \\
\hline
\end{tabular}

\section{Methods}

Ethics approval has been renewed annually since 2013 by the Committee on Human Research Subjects at the University of Guam (CHRS\#16-83).

\section{Study design, setting, and population}

The PICCS Study comprised of annual cross-sectional assessments of health indicators of college students at the University of Guam (UOG). Recruitment was held every fall semester from September to December since the pilot in 2013. Interviews were conducted on campus in a designated research room all study materials and equipment were kept secured.

PICCS welcomed any registered student at least 18 years old at the time of recruitment. Pregnant females were excluded due to potential challenges with anthropometric assessments. The target sample size each year was roughly $10 \%$ of the university's student population reported annually. ${ }^{8}$ The sample size in 2016 was 417 college students. Although sampling was non-random, efforts were made to recruit a representative sample of students according to the distribution of characteristics in the university fact book. Recruiters targeted all colleges and schools on campus.

\section{Data collection}

\section{Training}

Students majoring in Health Sciences beginning 2013 received training on the knowledge and skills pertinent to research ethics, planning, implementation, analysis, and dissemination of the PICCS through courses listed in Table 1. Initial years were spent developing the processes and establishing the infrastructure according to Fig. 1. Instructors remained principal investigators (PI) throughout. During junior and senior years, students were upgraded to coinvestigators and assumed one of the following roles: 1) Coordinator - Project Coordinator (assisted PI with trainings, scheduling, operations, logistics) or Data/Quality Assurance Coordinator (assisted PI with standardization, equipment calibration, survey completion); or 2) Collector - Recruiter (sought participants), Interviewer (administered questionnaires), or Measurer (collected body measurements). All student co-investigators practiced role-playing the informed consent process and administering the questionnaires several times before recruitment commenced each year. Measurers were trained and standardized to collect height and weight measurements using similar protocols from the Children's Health Living Program. ${ }^{9}$ Measurers who did not pass the standardization were encouraged to select from other co-investigator roles.

\section{Interview}

Interviews were conducted in pairs (interviewer and measurer). Data collected in 2016 included physical measurements and self-reported information. The physical data included: height measured in centimeters with a portable stadiometer (Model PE-AIM-101, Perspective Enterprises, Portage, MI) and weight measured in kilograms with a portable weight scale (SECA 876, Hamburg, Germany). The measurer performed the anthropometry and reported the numbers for the interviewer to record. Measurements continued until two consecutive measurements were within \pm 0.2 units.

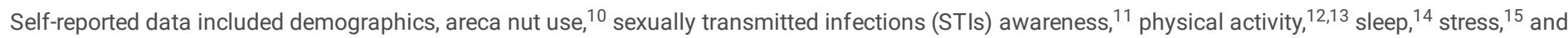
questions adopted from the Behavioral Risk Factor Surveillance System (BRFSS) including alcohol, dental visits, e-cigarettes, fruit and vegetable consumption, health care access, medical marijuana, and tobacco use. ${ }^{16}$

\section{Statistical analysis}

Data were entered in courses MA387 or HS451 or both depending on workload. Entries were reviewed and corrected by student co-investigators beside the initial data enterer. Data were analyzed with the SPSS Statistics Software. Body mass index (BMI) was calculated ((weight in kilograms) / (height in centimeters $(100)^{2}$ ). Weight status categories were determined as underweight (BMI<18.5), normal weight (18.5 to 24.9$)$, overweight (25.0 to 29.9$)$, and obese $(\geq 30) .{ }^{17}$ Ethnicity was recoded to reflect single Asian from any Asian country, single Pacific Islander from any Pacific Island, and Others including mixed ethnicity. Marital status was recoded to single, married, and other (divorced and common-law). Sleep was recoded into adequate ( $\geq 7$ hours) and inadequate ( $<7$ hours). Stress reflected the number of Yes responses to the stress experience assessment in Total Fitness \& Wellness, ${ }^{15}$ and recoded to high ( $\geq 6$ Yes responses) and low to average ( $<6$ Yes responses). Nutritional and physical activity variables were recoded: fast-food to frequent ( $\geq 3$ times per week) and infrequent ( $<3$ times per week), fruits and vegetables to frequent ( $\geq 3$ times per day) and infrequent ( $<3$ times per day), and physical activity via the Physical 
Activity Readiness Questionnaire ${ }^{12,13}$ to active (PARQ score $\geq 5$ ) and sedentary (PARQ score $<5$ ). Alcohol defined as any alcohol consumption in the last 30 days including binge drinking ( $\geq 5$ drinks for men or $\geq 4$ drinks for women on any occasion) and chronic drinking ( $\geq 60$ drinks in a month). Dental visits included frequent (within the past 12 months) and infrequent (> 12 months ago). Mean and standard deviation were calculated for ratio level variables. Frequency and percentages were calculated for categorical variables.

\section{Results}

\section{PICCS curriculum}

The PICCS produced positive outcomes since the concepts were initiated in 2013. A major success was the opportunity for students and faculty to present at national and local conferences. Of 33 abstracts submitted from 2015 to 2019 , 55\% were accepted for presentation. One manuscript led by students was recently published. ${ }^{18}$ Four student presentations were by invitation. Another success was the acceptance of students to summer programs. Of five student applicants to national public health leadership programs, $60 \%$ were accepted. Similarly, of three student applicants to a regional childhood prevention program, $67 \%$ were accepted. A final success of the PICCS framework was the acquisition of a grant award from the National Institute on Minority Health and Health Disparities in $2016 .{ }^{19}$ Additional funding via travel awards to students and faculty supported presentations at conferences throughout the US.

\section{Demographic characteristics, 2016}

In Table 2, the mean age of the 417 college students recruited in 2016 was $22.5 \pm 3.6$ years. Majority was female (54.9\%), single (95\%), and not employed for wages (52.3\%). The largest single ethnic group was Asian at 48.7\% (predominantly Filipino followed by Chinese and Korean), followed by Pacific Islander at 31.4\% (predominantly CHamoru followed by Chuukese, Pohnpeian, Palauan, Marshallese, and Yapese) and Other (predominantly White) and mixed ethnicity (CHamoru-Filipino) at 19.9\%.

Table 2. Demographic characteristics of study participants $(n=417)$ in the Pacific Islands Cohort of College Students (PICCS) Study, University of Guam, 2016

\begin{tabular}{ll}
\hline & Mean \pm Standard Deviation or Frequency (\%) \\
\hline $\begin{array}{l}\text { Age, years } \\
\text { Sex }\end{array}$ & $22.5 \pm 3.6$ \\
\hline Female & $229(54.9 \%)$ \\
\hline Male & $188(45.1 \%)$ \\
\hline Ethnicity & $203(48.7 \%)$ \\
\hline Asian, single race & $131(31.4 \%)$ \\
\hline Pacific Islander, single race & $83(19.9 \%)$ \\
\hline Other, including mixed & $396(95.0 \%)$ \\
\hline Marital status & $13(3.1 \%)$ \\
\hline Single & $8(1.9 \%)$ \\
\hline Married & \\
\hline Other & $199(47.7 \%)$ \\
\hline Employed for wages & $218(52.3 \%)$ \\
\hline Yes &
\end{tabular}

Ethnicity: Asian groups reported in majority order were Filipino, Chinese, and Korean. Pacific Islander groups reported in majority order were CHamoru, Chuukese, Pohnpeian, Palauan, Marshallese,

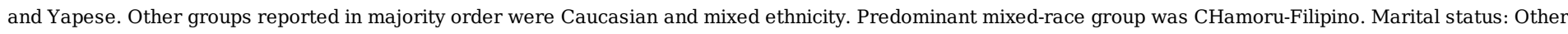
includes divorced and common-law.

\section{Health indicators, 2016}

In Table 3, majority of students reported access to health care (66.2\%) mostly through their parents' insurance, inadequate sleep (62.6\%), high stress (66.4\%), frequent fast food consumption (62.8\%), infrequent intake of fruits and vegetables (80.8\%), sedentary activity (63.8\%), alcohol consumption within the last 30 days (47\%) with $19.7 \%$ binge drinking and $4.6 \%$ chronic drinking, not using areca nut (93.5\%), not smoking cigarettes (90.9\%), not smoking e-cigarettes (84.4\%), not using medical marijuana (92.3\%), not chewing smokeless tobacco (92.1\%), and frequent dental visits (63.5\%). A high percentage was overweight (28.8\%) and obese (20.6\%).

Other high-risk health indicators were uninsured (26.9\%), areca nut users (5.1\%), cigarette smokers $(6.8 \%)$, e-cigarette smokers (14.1\%), medical marijuana users (5.0\%), smokeless tobacco chewers (5.5\%), and those who visited their dentist infrequently (32.6\%).

Table 3. Health indicators of study participants $(n=417)$ in the Pacific Islands Cohort of College Students (PICCS) Study, University of Guam, 2016 


\begin{tabular}{|c|c|}
\hline & Mean \pm Standard Deviation or Frequency (\%) \\
\hline \multicolumn{2}{|l|}{ HEALTH CARE ACCESS } \\
\hline No & $112(26.9 \%)$ \\
\hline Yes & $276(66.2 \%)$ \\
\hline Don't know & $28(6.7 \%)$ \\
\hline Refused & $1(0.2 \%)$ \\
\hline \multicolumn{2}{|c|}{ MENTAL HEALTH INDICATORS } \\
\hline \multicolumn{2}{|c|}{ Sleep } \\
\hline Adequate & $156(37.4 \%)$ \\
\hline Inadequate & $261(62.6 \%)$ \\
\hline \multicolumn{2}{|l|}{ Stress } \\
\hline High stress & $277(66.4 \%)$ \\
\hline Average stress & $139(33.3 \%)$ \\
\hline Missing & $1(0.2 \%)$ \\
\hline \multicolumn{2}{|c|}{ NUTRITIONAL AND PHYSICAL INDICATORS } \\
\hline \multicolumn{2}{|c|}{ Fast food } \\
\hline Frequent & $262(62.8 \%)$ \\
\hline Infrequent & $155(37.2 \%)$ \\
\hline \multicolumn{2}{|l|}{ Fruits and vegetables } \\
\hline Frequent & $80(19.2 \%)$ \\
\hline Infrequent & $337(80.8 \%)$ \\
\hline \multicolumn{2}{|l|}{ Physical activity } \\
\hline Active & $150(36.0 \%)$ \\
\hline Sedentary & $266(63.8 \%)$ \\
\hline Missing & $1(0.2 \%)$ \\
\hline \multicolumn{2}{|l|}{ Weight status } \\
\hline Underweight & $9(2.2 \%)$ \\
\hline Healthy weight & $190(45.6 \%)$ \\
\hline Overweight & $120(28.8 \%)$ \\
\hline Obese & $86(20.6 \%)$ \\
\hline Missing & $12(2.9 \%)$ \\
\hline \multicolumn{2}{|c|}{ ORAL HEALTH INDICATORS } \\
\hline \multicolumn{2}{|c|}{ Alcohol use } \\
\hline No & $193(46.3 \%)$ \\
\hline Yes & $196(47.0 \%)$ \\
\hline Binge drinking & $82(19.7 \%)$ \\
\hline Chronic drinking & $19(4.6 \%)$ \\
\hline Don't know & $18(4.3 \%)$ \\
\hline Refused/missing & $10(2.4 \%)$ \\
\hline \multicolumn{2}{|l|}{ Areca nut use } \\
\hline No & $390(93.5 \%)$ \\
\hline Yes & $21(5.1 \%)$ \\
\hline Don't know & $1(0.2 \%)$ \\
\hline Refused/missing & $5(1.2 \%)$ \\
\hline \multicolumn{2}{|l|}{ Cigarette smoking } \\
\hline No & 379 (90.9\%) \\
\hline Yes & $28(6.8 \%)$ \\
\hline Don't know & $2(0.5 \%)$ \\
\hline Refused/missing & $8(1.9 \%)$ \\
\hline \multicolumn{2}{|l|}{ E-cigarette use } \\
\hline No & $352(84.4 \%)$ \\
\hline Yes & $59(14.1 \%)$ \\
\hline Don’t know & $2(0.5 \%)$ \\
\hline Refused/missing & $4(1.0 \%)$ \\
\hline \multicolumn{2}{|l|}{ Medical marijuana } \\
\hline No & $385(92.3 \%)$ \\
\hline Yes & $21(5.0 \%)$ \\
\hline Don't know & $5(1.2 \%)$ \\
\hline & Page 5/12 \\
\hline
\end{tabular}




\begin{tabular}{cl} 
Refused/missing & $6(1.5 \%)$ \\
\hline Smokeless tobacco use & $131(31.4 \%)$ \\
\hline No & $384(92.1 \%)$ \\
\hline Yes & $23(5.5 \%)$ \\
\hline Don't know & $1(0.2 \%)$ \\
\hline Refused/missing & $9(2.2 \%)$ \\
\hline Visit dentist & \\
\hline Frequent & $265(63.5 \%)$ \\
\hline Infrequent & $136(32.6 \%)$ \\
\hline Don't know & $14(3.4 \%)$ \\
\hline Missing & $2(0.5 \%)$ \\
\hline
\end{tabular}

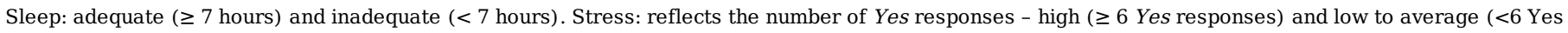

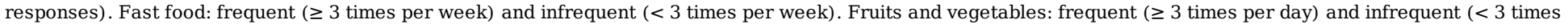

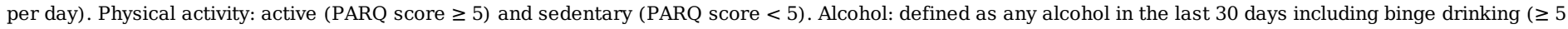

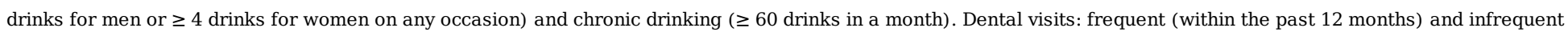
(>12 months ago).

\section{STI Awareness, 2016}

In Table 4, majority of students knew STI risk can be reduced by having sex with only one uninfected monogamous partner (68.1\%) or by using condoms (77.7\%). Most students knew a person could have/get the human immunodeficiency virus (HIV) even if the individual looked healthy (86.8\%), but could not acquire HIV from toilet seats (56.1\%) or by sharing food with an infected person (60\%). On the contrary, some students were unaware STIs can be reduced by having sex with only one uninfected monogamous partner (17\% misunderstood and $13.2 \%$ did not know) or by using condoms during every sexual encounter (12\% misunderstood and $8.6 \%$ did not know). Similarly, some students were unaware a person could have/get HIV even if the individual looks healthy (4.1\% misunderstood and $8.6 \%$ did not know), or could not get the HIV from toilets seats (18.9\% misunderstood and $24.5 \%$ did not know) or by sharing food with an infected person (16.3\% misunderstood and $23.3 \%$ did not know).

The most common source of information on STI and HIV testing and services was through a public health clinic (62.4\%), followed by the University campus (55.6\%), a private doctor (40.3\%), and the local Prutehi Hao social media (17.5\%). More than half of students did not obtain information on STI and HIV testing and services from a private doctor (55.9\%) or Prutehi Hao social media (78.7\%). Although students did not hear about STI and HIV testing and services on campus (40.5\%), the majority reported that condoms (90.9\%) and testing (78.4\%) should be available on campus.

Table 4. Awareness of sexually transmitted infection among study participants $(\mathrm{n}=417)$ in the Pacific Islands Cohort of College Students (PICCS) Study, University of Guam, 2016 
CAN THE RISK OF SEXUALLY TRANSMITTED INFECTIONS (STI) BE REDUCED BY:

Having sex with only one uninfected monogamous partner?

\begin{tabular}{ll} 
No & $71(17 \%)$ \\
Yes & $284(68.1 \%)$ \\
\hline Don't know & $55(13.2 \%)$ \\
Refused/missing & $7(1.7 \%)$
\end{tabular}

Using a condom during sex every time?

No $50(12.0 \%)$

Yes $324(77.7 \%)$

Don't know $36(8.6 \%)$

Refused/missing $7(1.7 \%)$

CAN A PERSON HAVE OR GET THE HUMAN IMMUNODEFICIENCY VIRUS (HIV):

If the individual looks healthy?

\begin{tabular}{ll} 
No & $17(4.1 \%)$ \\
Yes & $362(86.8 \%)$ \\
\hline Don't know & $36(8.6 \%)$ \\
\hline Missing & $2(0.5 \%)$ \\
\hline From toilet seats? & \\
\hline No & $234(56.1 \%)$ \\
Yes & $79(18.9 \%)$ \\
\hline Don't know & $102(24.5 \%)$ \\
Missing & $2(0.5 \%)$
\end{tabular}

By sharing food with someone who is infected?

No $250(60.0 \%)$

Yes $68(16.3 \%)$

Don't know 97 (23.3\%)

HAVE YOU HEARD ABOUT STI AND HIV TESTING SERVICES FROM:

A private doctor?

No $233(55.9 \%)$

Yes $168(40.3 \%)$

Missing $16(3.8 \%)$

A public health clinic?

No $141(33.8 \%)$

Yes $260(62.4 \%)$

Missing $16(3.8 \%)$

Prutehi Hao (local) social media

No $328(78.7 \%)$

Yes $73(17.5 \%)$

Missing $16(3.8 \%)$

On campus?

No $169(40.5 \%)$

Yes $232(55.6 \%)$

Missing 16 (13.8\%)

WHAT STI AND HIV SERVICES SHOULD BE AVAILABLE FOR STUDENTS ON CAMPUS?

Condoms

No $6(1.4 \%)$

Yes $379(90.9 \%)$

Don't know $29(7.0 \%)$

Refused/missing $3(0.7 \%)$

Testing

No $\quad 4(1.0 \%)$

Yes $391(78.4 \%)$

Don't know $20(4.8 \%)$

Missing $2(0.5 \%)$ 


\section{Teaching research to undergraduate students through the PICCS}

NCD morbidity and mortality are problematic even in the remote areas of the Pacific where challenges are further exacerbated by distance and limited resources. Incorporation of the PICCS in an undergraduate curriculum provided students with didactic and field training, thereby preparing them for graduate studies or the workforce. With guidance from program faculty, students were encouraged to identify relevant community health problems and suggest solutions through research and translation. Students took other non-core courses (e.g., BI100 Environmental Biology, PA210 Public Administration and Management Concepts, HS322 Kinesiology, and AL439 Community Nutrition) to supplement their interest. This interdisciplinary offering is reflective of "infusing public health education in the undergraduate curriculum" described by Rose in $2009 .{ }^{20}$ The PICcS curriculum provided most students their initial undergraduate research and leadership experience. Unlike the Centers for Disease Control and Prevention Undergraduate Public Health Scholars Program, ${ }^{21}$ the PICCS curriculum engages students over multiple undergraduate years.

\section{Identifying health risk behaviors of college students}

The 2016 PICCS data revealed that majority of students experienced several health risk behaviors including inadequate sleep (63\%), high stress (66\%), frequent fast-food consumption (63\%), infrequent fruit and vegetable intake (81\%), and sedentary activity levels (64\%). Overweight and obesity (49\%) was also a concern. Previous PICCS-related literature reported similar oral health behaviors, including alcohol consumption, smoking and smokeless tobacco use, and areca nut use, ${ }^{18}$ however, this paper is the first to document chronic drinking (5\%), electronic cigarette use (14\%), and medical marijuana use (5\%) among the PICCS participants.

\section{Inadequate sleep and high stress}

Sleep and stress are factors linked through biological mechanisms that researchers continue to investigate. According to the American Academy of Sleep Medicine and Sleep Research Society, seven hours of sleep in adults is the minimum threshold for optimal health. ${ }^{22}$ The $63 \%$ of students reporting inadequate sleep ( $<7$ hours per day) in the PICCS was above the one-third reported by adults in the 2014 US BRFSS even among those 18-24 years old. ${ }^{23}$ Interestingly, the inadequate sleep patterns in the PICCS fell in the adequate sleep patterns range of $56 \%$ in Hawaii to $72 \%$ in Colorado and South Dakota. ${ }^{23}$ Compared to other studies of college students, inadequate sleep in the PICCS (63\%) was still higher than other 18-24 year-old students across universities in the United States $(46 \%)^{24}$ and among student athletes (39\%). ${ }^{25}$

High stress was also reported in the PICCS. The relationship between sleep and stress has been suggested among healthy adults, ${ }^{26}$ medical students, ${ }^{27,28}$ mothers, ${ }^{29}$ and men, ${ }^{30}$ to name a few. The $66 \%$ of students reporting high stress in the PICCS was more than previous reports of college students in Guam ${ }^{31}$ and elsewhere, ${ }^{27,32}$ however, the tools used to measure stress varied between studies. The PICcS subsequently adopted the Depression Anxiety Stress Scale (DASS) to allow for comparability across studies. Work is underway to validate the DASS in the PICCS population.

\section{Poor nutrition, physical inactivity, and overweight and obesity}

Poor nutrition and physical inactivity are considered "public health enemy number two" (tobacco is number one) ${ }^{33}$ through obesity. The $21 \%$ of PICCS participants classified as obese was lower than the 2016 BRFSS Guam (28\%) and U.S. median (30\%); ${ }^{38}$ however, the PICCS represented measured height and weight while the BRFSS measurements were self-reported. Frequent fast-food consumption (63\%), infrequent fruit and vegetable intake (81\%), and sedentary activity levels (64\%) among PICCS participants are alarming and consistent with other college students in high fast-food consumption, ${ }^{34}$ low fruit and vegetable intake, ${ }^{35}$ and high sedentary behaviors. ${ }^{36}$ Obesity remains a global threat. To reverse the epidemic in the US, the CDC developed prevention strategies including nutrition and physical activity guidelines. ${ }^{37}$ These strategies should be considered, with input from college students, in interventions targeting college campuses.

\section{Initial reports of health risk behaviors by the PICCS}

This study documents the first reports of chronic drinking, e-cigarette use, medical marijuana use, and STI awareness among students in the PICCS. Most striking is e-cigarette use in the PICCS (14\%) was nearly twice that of Guam adults and nearly triple that of US adults in $2016 .{ }^{38}$ In contrast, medical marijuana use in the PICCS (5\%) was slightly lower than current use among US adults with (9\%) and without (8\%) medical conditions in $2016 .{ }^{39}$

STI awareness in this study represents the first collaborative research efforts on STIs between the University of Guam and the STI/HIV Program of the local health department. According to the CDC, adolescents and young adults aged 15-24 years comprised half of the new STI cases and two most common STIs were chlamydia and gonorrhea. ${ }^{40}$ Rate of reported chlamydia cases in Guam increased per 100,000 from 521 in 2014 to 662 in 2017 , followed by a decrease to 564 in $2018 .{ }^{40}$ Rate of reported gonorrhea cases also increased every year within the 5 -year period, from 62 to 156 per $100,000.40$

During the pilot test years of the PICCS, the health department's STI/HIV Program requested to assess STI awareness among college students who comprise the program's target population. Current PICCS findings suggest a lack of STI awareness (misconception or simply not knowing) exists among the college students. There is room for improvement in STI education and awareness efforts. STI outreach may be expanded to private doctors (for the $66 \%$ with health insurance access) and the public health clinic (for the $27 \%$ without health insurance). Despite its presence on social media, Prutehi Hao is not reaching the student population. The university is presented with an opportunity to improve STI education and awareness efforts, especially as most students support the distribution of condoms (91\%) and provision of STI testing services (78\%) on campus. Discussions are underway to incorporate STI testing as an option in the PICCS.

\section{Strengths and limitations}


Success of PICCS is attributed to its incorporation into the Health Science Program resulting in the sustainability of continuous collection, analysis, dissemination, and translation of health indicators of college students in Guam. The curriculum provides a hands-on approach to research from planning to dissemination with the opportunity to inform improvement. In exchange for their efforts, students receive undergraduate research experience that enhances their leadership capabilities, research and presentation skills, travel award and publication records, and confident to enter the workforce or graduate/postbaccalaureate programs. The PICCS framework provides the organizational structure and documented tools, protocols, roles, and responsibilities to ensure consistency and reproducibility.

The limitations are viewed as opportunities for improvement, such as the implementation of a longitudinal follow-up. The curriculum currently employs a cross-sectional study design limiting the interpretation of findings. A prospective follow-up will strengthen the study by allowing for incidence and risk measures. Other limitations included the non-random selection of students into the study and lengthy interviewer/interviewee interaction. Despite the nonrandom selection of students, the stratified sampling approach resulted in a demographic distribution like the university's student enrollment. To improve sampling efforts and reduce interview time, the PICCS team will explore recruitment via the registration office and conversion to online surveys.

\section{Conclusion}

The PICCS curriculum has resulted in multiple research successes including, 22 abstract presentations, one manuscript, five acceptances to summer healthleadership programs, four travel awards and one federal grant. Predominant health risk behaviors in 2016 were inadequate sleep (63\%), high stress (66\%), frequent fast-food consumption (63\%), infrequent fruit and vegetable intake (81\%), and sedentary lifestyle (64\%). Overweight and obesity (49\%) were also a concern. Incorporation of PICCS into an undergraduate curriculum presents an opportunity to monitor health risk behaviors among students and inform targeted intervention strategies.

\section{Declarations}

\section{Ethics approval and consent to participate}

This study was approved by the Committee on Human Research Subjects at the University of Guam (CHRS\#16-83). All protocols were carried out in accordance with relevant guidelines and regulations. Written informed consent was obtained from all participants in this study.

\section{Consent for publication}

Not applicable.

\section{Availability of data and materials}

Access to the PICCS data can be requested through the University of Guam, given compliance with ethical review requirements. Contact the corresponding author at paulinoy@triton.uog.edu.

\section{Competing interests}

The authors declare that they have no competing interests.

\section{Funding}

Not applicable.

\section{Authors' contributions}

Y.P. conceptualized the PICCS study, co-led the curriculum, and led the initial manuscript draft. A.A. co-led the PICCS study and curriculum. J.D. coordinated data collection and assisted with data analysis. E.B. assisted with data collection and data visual. K.C. assisted with data collection and data visual. B.C. assisted with data collection and literature review. A.D. coordinated data collection and assisted with data analysis. L.E. assisted with data collection and literature review. V.F. led manuscript revisions and formatting for submission. G.B. co-led the PICCS curriculum related to data analysis. M.U. co-led the PICCS curriculum. All authors critically reviewed the manuscript, provided feedback, and approved the manuscript.

\section{Acknowledgements}

We are grateful to the students in the University of Guam Health Science Program for their assistance with data collection and to Louis Dulana and Charlotte Mercado from the Mathematics Program for database development and data entry. The following students helped inform the manuscript structure: Aniceto Iglopas, Jr., Alfredo Mafnas, Luther Ponio, Leyann Simina, Oliver Sorio, Christopher Taimanglo, Muneka Taisipic, and Ryan Valencia. We thank the National Institutes of Health Building Infrastructure Leading to Diversity (BUILD) Enhancing Cross Disciplinary Infrastructure and Training at Oregon (EXITO) 1UL1MD009596-01 REVISED (Crespo-PI) Subaward:205CRE481 for providing participant compensation.

\section{Abbreviations}

PICCS Pacific Islands Cohort of College Students

NCDs Noncommunicable diseases 


\begin{tabular}{|c|c|}
\hline USAPIs & US-Affiliated Pacific Islands \\
\hline PIHOA & Pacific Health Officers' Association \\
\hline PCDC & Pacific Chronic Disease Council \\
\hline DDM & Pacific Data for Decision Making Program \\
\hline HS200 & Health and Wellness \\
\hline HS216 & Introduction to Public Health \\
\hline HS405 & Epidemiology \\
\hline HS416 & Research in Health Sciences \\
\hline MA387 & Statistics for Sciences \\
\hline HS451 & Research and Report Writing \\
\hline HS491 & Current Topics in Health Sciences \\
\hline HS498 & Internship in Health Sciences \\
\hline UOG & University of Guam \\
\hline PI & Principal investigator \\
\hline STIs & Sexually transmitted diseases \\
\hline BRFSS & Behavioral Risk Factor Surveillance System \\
\hline BMI & Body Mass Index \\
\hline PARQ & Physical Activity Readiness Questionnaire \\
\hline HIV & Human immunodeficiency virus \\
\hline BI100 & Environmental Biology \\
\hline PA210 & Public Administration and Management Concepts \\
\hline HS322 & Kinesiology \\
\hline AL439 & Community Nutrition \\
\hline DASS & Depression Anxiety Stress Scale \\
\hline
\end{tabular}

\section{References}

1. World Health Organization 2018. World Health Statistics 2018 Monitoring Health for the SDGs Sustainable Development Goals. 2018. https://apps.who.int/iris/bitstream/handle/10665/272596/9789241565585-eng.pdf?ua=1.

2. World Health Organization. Pacific Islanders Pay Heavy Price for Abandoning Traditional Diet. 2010. Bulletin of the World Health Organization. https://www.who.int/bulletin/volumes/88/7/10-010710/en/.

3. World Bank. Non-Communicable Disease (NCD) Roadmap Report (English). 2014. http://documents.worldbank.org/curated/en/534551468332387599/pdf/893050WP0P13040PUBLIC00NCD0Roadmap.pdf.

4. Untalan P. Pacific Islands Health Officers Association Board Resolution \#48-01. 2010. http://medicaid.as.gov/wp-content/uploads/2015/10/PIHOAResolution-48-01-NCD-Emergency-Declaration.pdf.

5. National Association of Chronic Disease Directors. Pacific Chronic Disease Council. About the USAPI. https://www.chronicdisease.org/page/PCDC.

6. Hoy D, Durand AM, Hancock T, et al. Lessons Learnt From a Three-Year Pilot Field Epidemiology Training Programme. West Pacific Surveillance and Response Journal. 2017; doi:10.5365/wpsar.2016.7.4.005.

7. Wilkins K, Nsubuga P, Mendlein J, Mercer D, Pappaioanou M. The Data for Decision Making Project: Assessment of Surveillance Systems in Developing Countries to Improve Access to Public Health Information. Public Health. 2008; doi:10.1016/j.puhe.2007.11.002.

8. University of Guam. 2017-2018 Fact Book. 2018.

https://www.uog.edu/_resources/files/administration/_institutional_effectiveness/AY2017_2018_FactBook_final_8218_wBookmarkTOCLink.pdf.

9. Li F, Wilkens L, Novotny R, et al. Anthropometric Measurement Standardization in the US-Affiliated Pacific: Report from the Children's Healthy Living Program. American Journal of Human Biology. 2016; doi:10.1002/ajhb.22796. 
10. Paulino Y, Novotny R, Katz A, Wilkens L, Hurwitz E. Development and Validation of an Areca (Betel) Nut Usage Measurement Tool for Micronesia [Abstract]. Proceedings of the Sixth American Association of Cancer Research Conference: The Science of Cancer Health Disparities in Racial/Ethnic Minorities and the Medically Underserved. 2013; doi:10.1158/1538-7755.DISP13-B15.

11. Schumann B. Guam Department of Public Health and Social Services Guam Public Health STD/HIV Program. 2015. http://www.prutehihao.com/about.html.

12. Jackson A, Blair S, Mahar M, Wier L, Ross R, Stuteville J. Prediction of Functional Aerobic Capacity Without Exercise Testing. Medicine \& Science in Sports \& Exercise. 1990; doi:10.1249/00005768-199012000-00021.

13. Paulino YC, Hurwitz EL, Ogo JC, et al. Epidemiology of Areca (Betel) Nut Use in the Mariana Islands: Findings From the University of Guam/University of Hawai'i Cancer Center Partnership Program. Journal of Cancer Epidemiology. 2017; doi:10.1016/j.canep.2017.08.006.

14. Buysse DJ, Reynolds CF, Monk TH, Berman SR, Kupfer DJ. The Pittsburgh Sleep Quality Index: A New Instrument for Psychiatric Practice and Research. Psychiatry Research. 1989; doi:10.1016/0165-1781(89)90047-4.

15. Powers S, Dodd S, Jackson E. Total Fitness \& Wellness. 6th ed. Boston: Pearson; 2014.

16. Centers for Disease Control and Prevention. Behavioral Risk Factor Surveillance System. https://www.cdc.gov/brfss/about/index.htm. Accessed 6 Feb 2020.

17. Centers for Disease Control and Prevention. Defining Adult Overweight and Obesity. https://www.cdc.gov/obesity/adult/index.html. Accessed 6 Feb 2020.

18. Nazareno N, Benavente A, Alicto M, et al. Smoking, Nutrition, Alcohol, Physical Activity, and Obesity (SNAPO) Health Indicators Among College Students in Guam. Hawai'i Journal of Health \& Social Welfare. 2020;79 6 Suppl 2:24-29.

19. PICCAH. Study Title: Pacific Islands Cohort on CArdiometabolic Health (PICCAH) U24 Study - A Cohort for Studying the Burden of Cardiometabolic Diseases in Guam and Pohnpei. https://www.uog.edu/piccah/about.php (2020).

20. Roe K. Infusing Public Health Education in the Undergraduate Curriculum: The Experience of a Comprehensive University. Association of American Colleges \& Universities. 2009. https://www.aacu.org/publications-research/periodicals/infusing-public-health-education-undergraduate-curriculum.

21. Office of Minority Health \& Health Equity (OMHHE). CDC Undergraduate Public Health Scholars (CUPS) Program. Centers for Disease Control and Prevention. https://www.cdc.gov/healthequity/features/cups/index.html.

22. Watson NF, Badr MS, Belenky G, et al. Joint Consensus Statement of the American Academy of Sleep Medicine and Sleep Research Society on the Recommended Amount of Sleep for a Healthy Adult: Methodology and Discussion. Journal of Clinical Sleep Medicine. 2015; doi:10.5664/jcsm.4950.

23. Liu Y, Wheaton AG, Chapman DP, Cunningham TJ, Lu H, Croft JB. Prevalence of Healthy Sleep Duration among Adults - United States, 2014. Morbidity and Mortality Weekly Report. 2016; doi:10.15585/mmwr.mm6506a1.

24. Quick V, Shoff S, Lohse B, White A, Horacek T, Greene G. Relationships of Eating Competence, Sleep Behaviors and Quality, and Overweight Status Among College Students. Eating Behaviors. 2015; doi:10.1016/j.eatbeh.2015.06.012.

25. Mah CD, Kezirian EJ, Marcello BM, Dement WC. Poor Sleep Quality and Insufficient Sleep of a Collegiate Student-Athlete Population. Sleep Health. 2018; doi:10.1016/j.sleh.2018.02.005.

26. Gunn HE, Critchfield KL, Mackaronis JE, et al. Affiliative Interpersonal Behaviors During Stress Are Associated With Sleep Quality and Presleep Arousal in Young, Healthy Adults. Sleep Health. 2017; doi:10.1016/j.sleh.2016.12.004.

27. Almojali Al, Almalki SA, Alothman AS, Masuadi EM, Alaqeel MK. The Prevalence and Association of Stress With Sleep Quality Among Medical Students. Journal of Epidemiology and Global Health. 2017; doi:10.1016/j.jegh.2017.04.005.

28. Alsaggaf MA, Wali SO, Merdad RA, Merdad LA. Sleep Quantity, Quality, and Insomnia Symptoms of Medical Students During Clinical Years. Relationship With Stress and Academic Performance. Saudi Medical Journal. 2016; doi:10.15537/smj.2016.2.14288.

29. McQuillan ME, Bates JE, Staples AD, Deckard KD. Maternal Stress, Sleep, and Parenting. Journal of Family Psychology. 2019; doi:10.1037/fam0000516.

30. Massar SAA, Liu JC, Mohammad NB, Chee MWL. Poor Habitual Sleep Efficiency Is Associated With Increased Cardiovascular and Cortisol Stress Reactivity in Men. Psychoneuroendocrinology. 2017; doi:10.1016/j.psyneuen.2017.04.013.

31. Ran M-S, Mendez AJ, Leng L-L, et al. Predictors of Mental Health Among College Students in Guam: Implications for Counseling. Journal of Counseling \& Development. 2016; doi:10.1002/jcad.12091.

32. Beiter R, Nash R, McCrady M, et al. The Prevalence and Correlates of Depression, Anxiety, and Stress in a Sample of College Students. Journal of Affective Disorders. 2015; doi:10.1016/j.jad.2014.10.054.

33. Schneider M-J. Introduction to Public Health, 4th ed. Jones \& Bartlett Learning; 2014.

34. Haines C, O'Neil CE, Zanovec M. Fast-Food Consumption Among College Students and Their Attitudes Toward Healthier Fast-Food Options. Federation of American Societies for Experimental Biology Journal. 2010; doi:https://doi.org/10.1096/fasebj.24.1_supplement.940.4.

35. Oregon State University. College Students Not Eating Enough Fruits and Veggies, Study Finds. 2011. https://www.sciencedaily.com/releases/2011/08/110817142847.htm\#: :text=College\%20students\%20not\%20eating\%20enough\%20fruits\%20and\%20ve! Date\%3A\%20August\%2019\&text=Summary\%3A\&text=\%22We\%20found\%20that\%20students\%20skipped,one\%20of\%20the\%20study's\%20authors.

36. Franco DC, Ferraz NL, de Sousa TF. Sedentary Behavior Among University Students: A Systematic Review. Brazilian Journal of Kinanthropometry and Human Performance. 2019; doi:http://dx.doi.org/10.5007/1980-0037.2019v21e56485.

37. Centers for Disease Control and Prevention. Overweight \& Obesity: Prevention Strategies \& Guidelines. 2018. https://www.cdc.gov/obesity/resources/strategies-guidelines.html. Accessed 21 Jul 2020. 
38. Centers for Disease Control and Prevention. BRFSS Prevalence \& Trends Data. 2017. https://www.cdc.gov/brfss/brfssprevalence/index.html. Accessed $21 \mathrm{Jul} 2020$.

39. Dai H, Richter KP. A National Survey of Marijuana Use Among US Adults With Medical Conditions, 2016-2017. JAMA Network Open. 2019; doi:10.1001/jamanetworkopen.2019.11936.

40. US Department of Health and Human Services, Centers for Disease Control and Prevention, National Center for HIV/AIDS, Viral Hepatitis, STD, and TB Prevention, Division of STD Prevention. Sexually Transmitted Disease Surveillance 2018. 2019; doi:10.15620/cdc.79370.

\section{Figures}

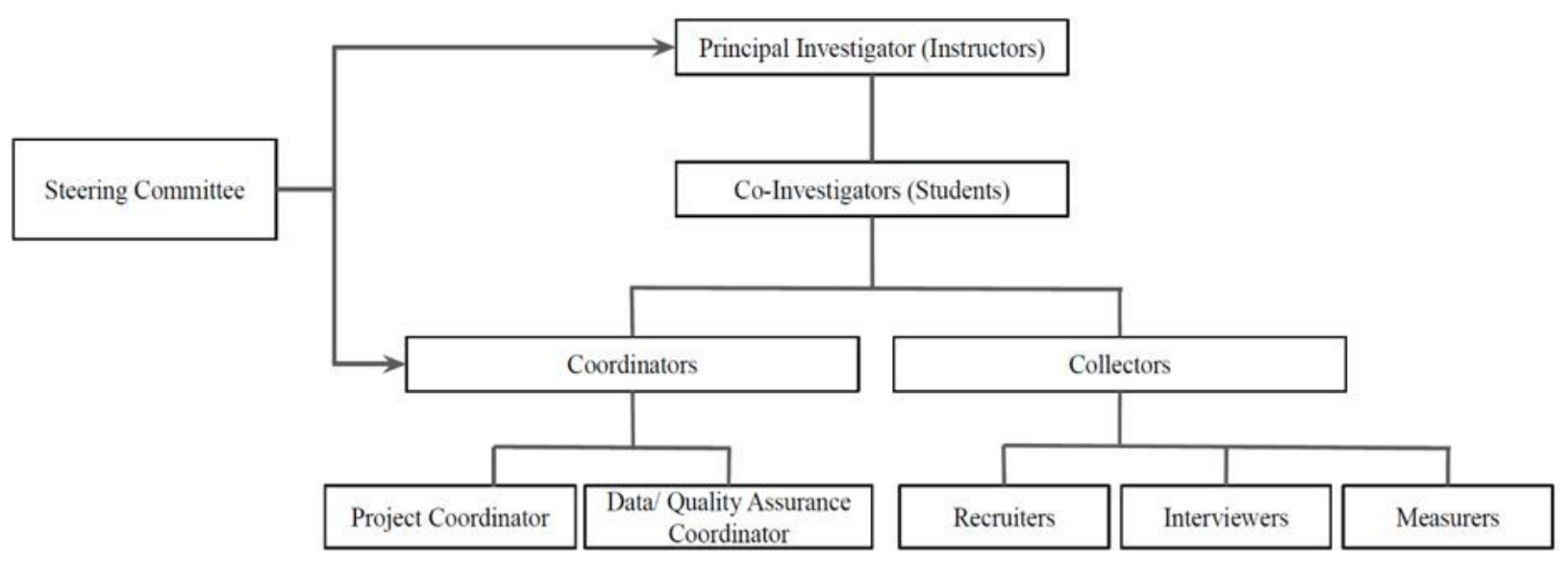

Figure 1

Organizational framework of the data collection team of the Pacific Islands Cohort of College Students (PICCS) curriculum of the B.S. Health Sciences Program, University of Guam 